\title{
Molecular imaging of the atherosclerotic plaque using positron emission tomography
}

\author{
${ }^{1}$ IS Toor, ${ }^{2} \mathrm{MR}$ Dweck, ${ }^{3} \mathrm{DE}$ Newby \\ ${ }^{1}$ Edinburgh Clinical Academic Training Clinical Lecturer; ${ }^{2}$ British Heart Foundation (BHF) Clinical Lecturer; ${ }^{3} B H F$ John Wheatley Professor \\ of Cardiology, BHF/University of Edinburgh Centre for Cardiovascular Science, University of Edinburgh, UK
}

\begin{abstract}
Accurately assessing an individual's risk of myocardial infarction or stroke using currently available risk stratification tools remains a challenge, even in patients with symptomatic disease. Inflammation, micro-calcification and intra-plaque angiogenesis occur during the development and ultimate rupture of vulnerable plaques. Molecular imaging techniques such as combined positron emission tomography and computed tomography (PET/CT) offer the opportunity to target these key cellular processes within atheroma and identify high-risk lesions. In this review we will set out the studies that have demonstrated the feasibility of PET/CT imaging in assessing atherosclerotic plaque inflammation, micro-calcification and angiogenesis. We will also discuss the potential of PET/CT molecular imaging as both a screening tool for novel therapeutic interventions and as a means of improving cardiovascular risk stratification.
\end{abstract}

KEYWORDS angiogenesis, inflammation, micro-calcification positron emission tomography, vulnerable plaque,

DECLARATIONS OF INTERESTS Dr Toor is supported by the Wellcome Trust, Dr Dweck and Prof Newby are supported by the British Heart Foundation ( $\mathrm{CH} / 09 / 002)$.
Correspondence to DE Newby British Heart Foundation/

University Centre for Cardiovascular Science University of Edinburgh Chancellor's Building 49 Little France Crescent Edinburgh EHI 6 4SB, UK

tel +44 (0) I3I 24265 I5 e-mail d.e.newby@ed.ac.uk

\section{INTRODUCTION}

Atherosclerosis is dependent on a number of cellular processes from initial endothelial injury to sequestration of lipid in the subendothelial space and activation of immune cells.' Risk factors for predicting the development of atherosclerosis are well established, as are the various imaging techniques available to assess the burden of atherosclerosis in patients with symptomatic disease. ${ }^{2}$ However, accurately assessing an individual's risk of acute complications even in patients with symptomatic atherosclerosis remains a challenge.

Knowledge of the cellular processes involved in atherosclerosis has been used to identify blood borne biomarkers in order to risk stratify patients. ${ }^{3} \mathrm{~A}$ similar approach is currently being applied to molecular imaging modalities such as positron emission tomography (PET). ${ }^{4}$ With the additional anatomical information provided by imaging modalities, there is potential to direct risk stratification to the level of the individual atherosclerotic plaque. Molecular imaging of atherosclerosis using PET is currently at the stage where it is being applied as a biomarker in drug development and has potential to make the transition into clinical medicine to aid cardiovascular risk stratification. ${ }^{5,6}$

\section{POSITRON EMISSION TOMOGRAPHY IMAGING}

Positron emission tomography imaging uses ionising radiation to localise specific cellular processes in the body with a spatial resolution of $\sim 4 \mathrm{~mm}$. It combines a positron emitter with a molecular vehicle targeting a cellular process of interest. I8F-Fluoride is the most practical and commonly used positron emitter because it has a half-life of $110 \mathrm{~min}$. A PET image is formed by the detection of two photons with a specific energy emitted following the collision of an electron with a positron arising from the fluoride nucleus. ${ }^{7}$ This annihilation event produces two photons at 180 degrees from each other. Their simultaneous detection helps to build a 3D image of positron emission events and localise the anatomical site where the tracer has accumulated. ' Such PET images are then fused with CT allowing activity to be localised to even small structures within the body. ${ }^{8}$

The dominant features of vulnerable atherosclerotic plaque include a thin fibrous cap and large necrotic core with a predominance of foam cells, macrophages and apoptotic bodies.' There is also evidence of microcalcification associated with the necrotic core and intra-plaque angiogenesis, which may lead to haemorrhage and plaque instability. By targeting plaque macrophage density, micro-calcification and angiogenesis, it is hoped that in vivo molecular imaging with 


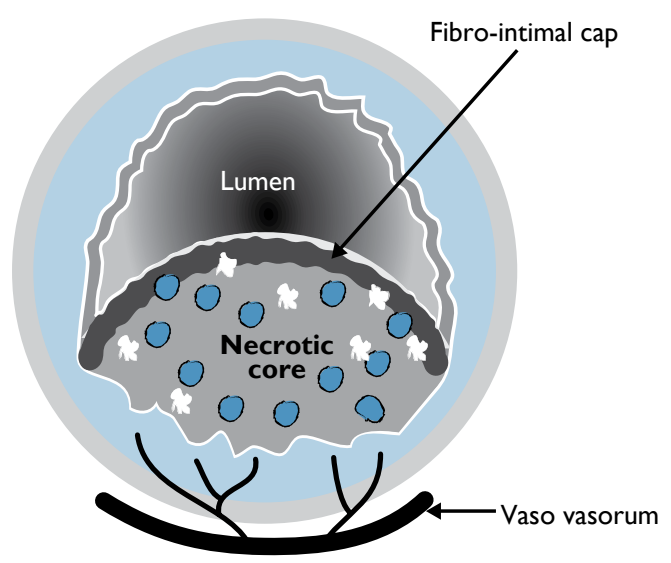

I Plaque inflammation:

Glucose analogue: fluorodeoxyglucose

Macrophage translocator protein: PKIII 95

Macrophage mannose receptor: fluorodeoxymannose

2 Micro-calcification:

Hydroxyapatite: sodium fluoride

3 Intra-plaque neovascularisation:

Endothelial $\alpha_{v} \beta_{3}$ integrin receptor: galacto and

fluciclatide

Macrophage infiltration

Micro-calcification

Micro-vessel

FIGURE I Characteristics of vulnerable atherosclerotic plaque alongside potential positron emission tomography radiotracers capable of identifying such lesions.

PET tracers will help identifying vulnerable plaques prior to rupture (Figure I).

\section{FLUORODEOXYGLUCOSE AS A BIOMARKER OF PLAQUE INFLAMMATION}

Positron emission tomography imaging with the tracer I8F-fluorodeoxyglucose (I8F-FDG) is currently used in clinical practice to assess myocardial viability. ${ }^{9}$ I8F-FDG is a glucose analogue that accumulates in cells proportional to their glycolytic activity. Macrophages are the most abundant cell within the atherosclerotic plaque and have a higher glucose metabolism than surrounding plaque cells. Therefore, the I8F-FDG signal from atherosclerotic plaques is regarded as a marker of plaque macrophage inflammation. ${ }^{10}$

Macrophages are implicated in every stage of atherosclerosis from its initiation and progression through to clinical plaque rupture events. Histological examination of ruptured plaques demonstrates an abundance of macrophages, particularly in the shoulder regions where they secrete matrix metalloproteinases, weakening the fibrous caps and predisposing these sites to rupture. Indeed, Rudd et al. first demonstrated increased focal I8F-FDG uptake within culprit atherosclerotic plaques in patients with symptomatic carotid disease." Carotid plaques ipsilateral to the neurological event were found to have $27 \%$ higher I8FFDG uptake relative to the asymptomatic contra-lateral artery." Ex vivo examination using carotid plaque autoradiography confirmed selective accumulation of deoxyglucose within macrophage-rich areas of plaques."

There is also a close correlation between I8F-FDG uptake and both the absolute and percentage of macrophage accumulation within plaque sections. ${ }^{12}$ Moreover, gene expression analysis from carotid plaques demonstrates an association between I8F-FDG uptake and markers of plaque instability including CD68, GLUTI, HK-I2 and cathespin K.13 However, recent data also indicate that I8F-FDG accumulation may reflect the degree of hypoxia within plaques, which encourages glycolytic rather than oxidative metabolism and increased tracer uptake. ${ }^{14}$

I8F-FDG uptake is associated with traditional cardiovascular risk factors, including age, male gender and metabolic syndrome, as well as inflammatory biomarkers. ${ }^{15,16}$ Moreover, vascular I8F-FDG uptake is elevated in patients infected with human immunodeficiency virus, perhaps accounting for their increased cardiovascular event rate. ${ }^{17-19} \mathrm{~A}$ retrospective review of vascular I8FFDG uptake on PET scans performed in patients with cancer has demonstrated an association between I8FFDG uptake and subsequent vascular events. ${ }^{20}$

However, the predictive power of I8F-FDG uptake over and above that of conventional cardiovascular risk factors remains to be established prospectively. This is being addressed in studies such as High Risk Plaque Initiative and Biolmage, which will assess whether imaging biomarkers including I8F-FDG imaging are able to risk stratify patients beyond that achieved with traditional cardiovascular risk factors. ${ }^{5,21}$ However, using I8F-FDG imaging as a longitudinal marker of cardiovascular risk may be limited by the variation of the vascular I8F-FDG signal over time (perhaps reflecting waxing and waning of plaque inflammation) and by the associated radiation exposure making its less attractive as a screening tool in low-risk populations. ${ }^{22}$

I8F-FDG PET does hold considerable promise as a method of evaluating the efficacy of novel antiatherosclerotic treatments. Small studies have demonstrated that statin therapy and lifestyle 
modification reduces plaque I8F-FDG activity. ${ }^{23,24}$ Moreover, I8F-FDG imaging has been used as a safety end-point to demonstrate the feasibility of novel lipid treatments and demonstrated their lack of impact on vascular inflammation. ${ }^{25}$ Currently, I8F-FDG is being used in multiple ongoing clinical trials of novel agents with the aim of evaluating vascular safety, detecting early signs of biological effect and understanding the mechanism of action of novel therapies.

While I8F-FDG imaging has now been validated in the aorta and carotid, iliac and femoral arteries, ${ }^{26,27}$ attempts to use this tracer in the coronary arteries have been less successful. Initial studies were encouraging, with I8FFDG activity in the proximal vessels and adjacent aorta demonstrating increased activity in patients following acute coronary syndromes compared with those with stable angina..$^{28,29}$ However, attempts to examine the coronary vasculature in more detail have been limited by the glycolytic activity of the myocardium, which uses glucose as its predominant energy source and therefore avidly takes up I8F-FDG obscuring any signal in adjacent structures. High-fat, low-carbohydrate diets have been used in an attempt to switch myocardial metabolism to free fatty acid and reduce ventricular uptake. ${ }^{30}$ However, these measures have proved only modestly effective, with background myocardial I8F-FDG activity remaining a significant problem in almost half of patients. ${ }^{29,30}$

We believe that this lack of specificity is likely to limit the use of I8F-FDG as a biomarker of coronary artery disease risk and that more macrophage specific tracers are required. The novel radio-ligand I IC-PK I I 95 holds promise in this regard, targeting a translocator protein specific to human macrophages and demonstrating increased uptake in atherosclerotic plaques that correlates with macrophage infiltration. ${ }^{31}$ Targeting cell surface receptors distinct to macrophage subtypes may enhance the specificity of imaging plaque inflammation. This approach to refinement has been taken with I8F-fluorodeoxymannose (FDM), which is an analogue of glucose but also binds to mannose receptors present on alternatively activated (M2) macrophages. ${ }^{32}$ The M2 macrophages are associated with high-risk plaque features such as neovascularisation and intra-plaque haemorrhage. $^{32}$ By targeting mannose receptors expression in addition to plaque glucose metabolism, I8F-FDM is potentially able to both quantify and characterise plaque inflammation.

\section{SODIUM FLUORIDE IMAGING AS A BIOMARKER OF MICRO-CALCIFICATION}

Calcification is a key hallmark of the atherosclerotic plaque that was previously thought to be a generalised passive process associated with age-related degeneration.' However, extra-skeletal calcification in other areas of the body is commonly seen in conjunction with chronic inflammation such as granulomatous infections and chronic inflammatory connective tissue disorders. Similarly, calcification in atherosclerosis is now believed to occur as a healing response to the potent inflammatory stimulus in the necrotic core. ${ }^{33}$ While ultimately the latter stages of macro-calcification seen in atherosclerosis are believed to impart stability to the plaque, the early stages of microcalcification are associated with increased plaque vulnerability and tendency to rupture..$^{34}$

Computed tomography coronary artery calcium score (CAC) is a widely used measure of vascular calcification. ${ }^{35}$ Calcium in the coronary arteries is pathognomonic of atherosclerosis, so CAC scoring provides a useful surrogate of a patient's coronary atherosclerotic burden. ${ }^{2}$ Moreover, it is a useful predictor of cardiovascular events since the more plaques a patient has, the more likely they are to have a clinical plaque rupture event. It is not, however, capable of identifying high-risk vulnerable lesions directly. ${ }^{36}$

Indeed, intravascular ultrasound and CT studies demonstrate that culprit coronary artery lesions in patients with acute coronary syndromes have less extensive coronary calcification in comparison with lesions associated with chronic stable angina. ${ }^{37,38}$ This would suggest that macro-calcification of a plaque, which is measurable by the CAC score, is protective and has a role in plaque stability. However, biomechanical modelling indicates that regions of micro-calcification have the opposite effect and predispose to plaque rupture. Areas of micro-calcification within the fibrous cap can create an interface between the rigid and compliant structures of the cap that intensifies the effect of incident haemodynamic forces resulting in plaque rupture. ${ }^{39} \mathrm{With}$ progressive calcification the areas of interface would decrease and so at this point the risk of rupture would be expected to decrease as plaque calcification becomes increasingly confluent and the cap more rigid.

It has also been demonstrated that hydroxyapatite micro-particles are able to activate human macrophages. Macrophages have a greater capacity to endocytose hydroxyapatite micro-particles with a more complex nanotopography and larger surface area for attachment and phagocytosis. ${ }^{40}$ Micro-calcification would therefore appear an excellent marker of high-risk atherosclerotic plaque at risk of rupture. Indeed histological studies have demonstrated an association of micro-calcification with both ruptured plaques and also high-risk lesions with large necrotic cores. ${ }^{34}$ Consequently, techniques capable of detecting micro-calcification non-invasively and differentiating it from more advanced regions of macrocalcification could potentially prove useful in identifying vulnerable regions of atheroma.

The PET tracer I8F-sodium fluoride (I8F-NaF) has been used as a bone tracer for more than 40 years. It acts as 
a biomarker for hydroxyapatite, which is a key structural component of both bone and vascular calcification. It forms a chemical bond to exposed hydroxyapatite by replacing the hydroxyl group with fluoride to form fluoroapitate. ${ }^{41}$ The degree of $18 \mathrm{~F}-\mathrm{NaF}$ uptake is dependent on the surface area of the hydroxyapatite crystalline structure. Transmission electron microscopy demonstrates that during the early stages of vascular calcification formation hydroxyapatite crystals are nanosized, very thin and long. ${ }^{42}$ This results in an enormous surface area of nanocrystals to which $18 \mathrm{~F}-\mathrm{NaF}$ can bind. As a consequence of this surface area effect $18 \mathrm{~F}-\mathrm{NaF}$ preferentially binds to regions of powdery microcalcification as opposed to field macroscopic calcification where much of the hydroxyapatite is internalised and not available for binding.

Initial evidence for vascular uptake of $18 \mathrm{~F}-\mathrm{NaF}$ was provided by retrospective reviews of PET scans performed in patients with cancer. Its uptake was found in the large vessels, including the aorta and carotid, iliac and femoral arteries. ${ }^{43-46}$ Our group demonstrated cardiac uptake of $18 \mathrm{~F}-\mathrm{NaF}$ in patients with calcific aortic valve disease. ${ }^{47}$ Areas of $18 \mathrm{~F}-\mathrm{NaF}$ uptake in calcific aortic stenosis were frequently remote from established calcification identified on CT imaging. ${ }^{47}$ This was the first indication that $18 \mathrm{~F}-\mathrm{NaF}$ could be used to differentiate between vascular micro- and macro-calcification. This finding is supported by our recent observations using serial I8F-NaF PET/CT imaging of patients with asymptomatic aortic stenosis. We found baseline valvular I8F-NaF uptake predicted the development of new areas of macro-calcification and the progression in aortic valve calcium scores on follow-up CT after one year. ${ }^{48}$

We demonstrated the feasibility of imaging coronary I8F$\mathrm{NaF}$ uptake in a prospective study of 119 patients with and without aortic valve disease. ${ }^{49}$ 18F-NaF imaging of coronary arteries was not hindered by myocardial uptake and so could be reliably measured with excellent intraand inter-observer variability. The $18 \mathrm{~F}-\mathrm{NaF}$ signal was higher in patients with coronary artery atherosclerosis and discrete areas of $18 \mathrm{~F}-\mathrm{NaF}$ uptake could be localised to individual coronary plaques. ${ }^{49}$ Interestingly, I8F-NaF uptake correlated with the Framingham risk score, suggesting its association with a higher cardiovascular risk profile. Indeed, stratification of the patients with coronary artery disease using $18 \mathrm{~F}-\mathrm{NaF}$ uptake demonstrated that those with increased uptake were more likely to have symptomatic coronary artery disease and a history of major adverse cardiovascular events. ${ }^{49}$

Our group has recently gone on to investigate whether $18 \mathrm{~F}-\mathrm{NaF}$ activity in patients with unstable atherosclerotic disease localises to ruptured culprit lesions. ${ }^{6}$ In this study patients with recent acute myocardial infarction (MI) underwent both invasive coronary angiography and I8F-NaF imaging. The I8F-NaF signal localised to the site

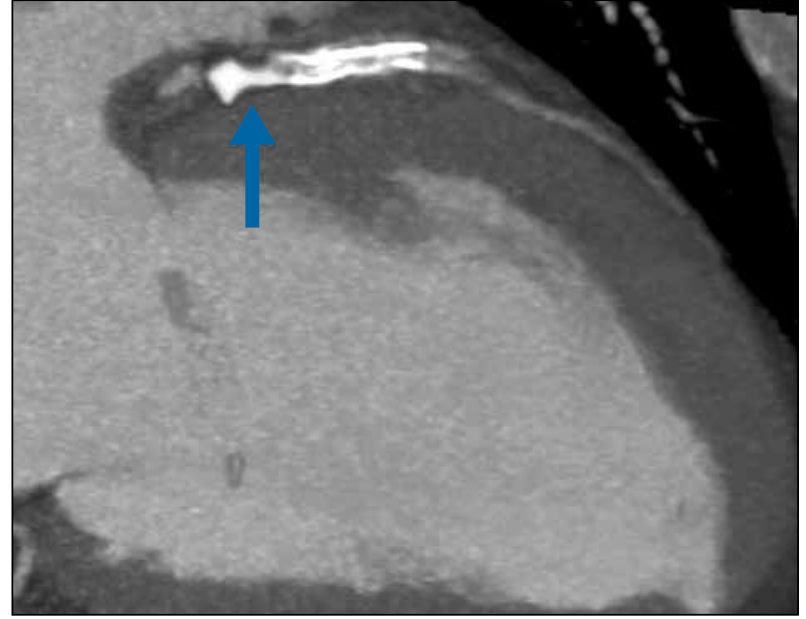

FIGURE 2 Focal I8F-NaF uptake localising to the culprit atherosclerotic plaque responsible for a patient's acute myocardial infarction. Intense focal I8F-NaF (I8F-NaF, tissue-to-background ratios, culprit 2.17 versus reference segment 1.18 [184\% increase]) uptake (yellow-red) at the site of the culprit plaque (red arrow) on the combined PET-CT image.

of coronary plaque rupture in 37 of the 40 (93\%) patients (Figure 2). Of the remaining three patients without culprit lesion uptake, two were young smokers who may have suffered an event due to plaque erosion rather than rupture. The third patient had a co-dominant circulation, and while the right coronary artery was adjudicated on angiography as the culprit, focal increased $18 \mathrm{~F}-\mathrm{NaF}$ activity was instead observed in the left circumflex artery that might have equally explained the clinical presentation. The localisation of $18 \mathrm{~F}-\mathrm{NaF}$ to ruptured atherosclerotic plaques was then confirmed in symptomatic patients undergoing carotid endarterectomy following transient ischaemic attack or stroke. Ex vivo $18 \mathrm{~F}-\mathrm{NaF}$ imaging of excised carotid plaques from nine patients demonstrated tracer uptake localised to the site of macroscopic plaque rupture. Both of these studies suggest that ruptured atherosclerotic plaques in patients with symptomatic coronary and carotid disease appear to have increased focal I8F-NaF uptake.

It is not feasible to perform histological examination of coronary plaques in patients with recent MI. Therefore, excised carotid plaques were again used to correlate vascular $18 \mathrm{~F}-\mathrm{NaF}$ uptake with histological findings in order to get an understanding of the mechanism of tracer uptake. ${ }^{6}$ Carotid plaques were sectioned into areas with and without $18 \mathrm{~F}-\mathrm{NaF}$ uptake. Plaque sections with increased 18F-NaF uptake had evidence of increased calcification activity, inflammation as determined by macrophage infiltration, and cell death (both necrosis and apoptosis). ${ }^{6}$ This would support the hypothesis that microcalcification occurs as a healing response to the intense inflammation in the necrotic core that also triggered the plaque rupture event. An alternative interpretation is that calcification occurs as healing response to the plaque rupture event itself. However, we do not believe this is the 
explanation because of the short time interval between $\mathrm{Ml}$ and the PET imaging, and the fact that iatrogenic plaque rupture induced by stenting of bystander lesions did not result in increased I8F-NaF activity.

While it is interesting that I8F-NaF can identify culprit atherosclerotic plaque, the key question is whether it can identify these lesions prospectively before they cause clinical events. We therefore examined coronary I8F-NaF uptake in a group of high-risk patients with stable disease. ${ }^{6}$ Focal regions of increased coronary I8F$\mathrm{NaF}$ uptake were observed in more than two out of five (18/40; 45\%) patients with stable angina, most commonly (72\%) in non-obstructive ( $<70 \%$ stenosis) lesions on coronary angiography. Following I8F-NaF coronary imaging, the morphology of coronary plaques with I8F$\mathrm{NaF}$ uptake was evaluated using radio-frequency intravascular ultrasound and CT coronary angiography. ${ }^{6}$ Plaques with $18 \mathrm{~F}-\mathrm{NaF}$ uptake were associated with highrisk features including micro-calcification $(73 \%$ versus $22 \%$; $=0.002)$, a larger necrotic core $(24.6 \%$ [interquartile range (IQR) 20.5-28.8] versus $18.0 \%$ [14.0-22.4]; $\mathrm{p}=0.00 \mathrm{I}$ ) and positive remodelling (remodelling index I.I 2 [IQR I.069-I.I9] versus I.0I [0.94-I.06]; $\mathrm{p}<0.00$ I). In contrast I8F-NaF negative plaques had features associated with a stable morphology such as being composed of more fibrous (5I.0\% [IQR 46.3-56.6] versus $58.1 \%$ [5I.6-65.5]; $\mathrm{p}=0.015)$ and fibro-fatty tissue (10.9\% [6.0-13.8] versus $12.6 \%[9.3-17.8] ; p=0.09)$ and greater confluent areas of calcification (12.6\% [9.1-18.1] versus $10.2 \%[4.0-\mid 4.9] ; p=0.09)$.

I8F-NaF imaging holds promise as a non-invasive imaging technique that can risk stratifying atherosclerotic plaque by identifying active micro-calcification occurring in response to intense necrotic inflammation. However prospective studies are now required to confirm whether those plaques with increased I8F-NaF activity go on to cause future cardiovascular events and whether they can identify high-risk patients who would benefit from aggressive medical therapy.

\section{ATHEROSCLEROTIC PLAQUE NEOVASCULARISATION}

Medium and large size arteries are accompanied by vasa vasorum, which form a network of microvasculature in the adventitial layer and supply oxygen and nutrients to the vessel wall. Proliferation of adventitial vasa vasorum occurs in areas of atherosclerosis and leads to neovascularisation of the media and intima. ${ }^{50}$ While neovascularisation can occur even before endothelial dysfunction (perhaps suggesting that this may be an initiating event in the development of atherosclerosis) the predominant trigger is believed to be the progressively hypoxic conditions that develop within the plaque as it enlarges. ${ }^{51}$ Indeed once the plaque thickness exceeds a critical limit of $\sim 100 \mu \mathrm{m}$, the capacity for diffusion of blood oxygen and nutrients from the lumen is limited and new vessels are required..$^{52}$ As a consequence while microvessels are observed in around $40 \%$ of coronary atherectomy specimens, they are much more frequently observed in thicker carotid lesions. ${ }^{53}$

Intra-plaque angiogenesis is an independent predictor of plaque rupture and associated with intra-plaque haemorrhage. ${ }^{54}$ It therefore has potential as an imaging biomarker for identification of vulnerable plaques. Newly formed microvessels do not have supporting cells and so are fragile and permeable. Intra-plaque haemorrhage following the extravasation of erythrocytes from fragile new microvessels is relatively common and microvessel density correlates with the extent of intra-plaque haemorrhage. ${ }^{55,56}$ The cell membrane of extravasated erythrocytes contributes a rich source of free cholesterol and cholesterol ester which leads to enlargement of the necrotic core and rapid progression of atherosclerosis. ${ }^{56,57}$ However, intra-plaque angiogenesis is not the only source of plaque haemorrhage. It can also result from plaque fissuring following rupture of a fibrous cap with the subsequent formation of an intra-intimal thrombus. ${ }^{55}$

As mentioned previously, inflammation and infiltration of macrophages are prominent features of the vulnerable plaque.There is a strong correlation between microvessel density and histological content of macrophages in carotid artery plaques. ${ }^{58}$ It is believed that the microvessels are used by inflammatory cells to enter the atherosclerotic plaque. ${ }^{59}$ Indeed, unstable coronary atherosclerotic plaques are associated with a higher microvessel density with a two-fold increase in vulnerable plaques and a four-fold increase in ruptured plaques in comparison with stable lesions. ${ }^{56,57}$ Furthermore, microvessel density is found to be higher in the vulnerable shoulder region of atherosclerotic plaques. ${ }^{54}$ Overall, intra-plaque angiogenesis appears to correlate with key features of the vulnerable plaque that are associated with plaque rupture.

How then can we image angiogenesis? New blood cells express the cell surface integrin receptors $\alpha_{v} \beta_{3}$ and $\alpha_{v} \beta_{5}$, which recognise the arginine-glycine-aspartate (RGD) motif. ${ }^{60}$ On this basis the RGD-containing PET tracers I8F-galacto and 18F-fluciclatide, have been developed to target the $\alpha_{\nu} \beta_{3}$ integrin receptor and detect angiogenesis. ${ }^{61,62}$ At present 18F-galacto has been validated as a biomarker for $\alpha_{v} \beta_{3}$ integrin expression in atherosclerotic plaques of patients with significant carotid artery stenosis. ${ }^{63}$ Ex vivo histological studies on carotid endarterectomy specimens demonstrated that I8F-galacto correlated with both angiogenic endothelial cells and macrophages expressing $\alpha_{v} \beta_{3}$ integrin. It therefore appears to act as a marker of both plaque inflammation and angiogenesis holding promise as a method of risk stratifying carotid plaque, although whether it will be detectable in the coronary arteries remains to be established. ${ }^{64}$ 


\section{CONCLUSION}

Our understanding of plaque biology is directing the development of imaging biomarkers. The currently available PET tracers offer the potential to assess in vivo the pathological processes that underlie the vulnerable plaque. A direct measure of disease activity with $18 \mathrm{~F}$ FDG imaging could potentially be used to screen novel therapeutic interventions and assess their efficacy before investing in large multi-centre clinical trials. Newer radiotracers are attempting to target the distinct cellular constituents of the vulnerable plaque and so enhance

\section{REFERENCES}

I Libby P, Ridker PM, Hansson GK. Progress and challenges in translating the biology of atherosclerosis. Nature 201 I; 473:31725. http://dx.doi.org/I0.1038/nature I0I46

2 Task Force Members, Montalescot G, Sechtem U et al. 2013 ESC guidelines on the management of stable coronary artery disease: the Task Force on the management of stable coronary artery disease of the European Society of Cardiology. Eur Heart J 2013 34:2949-3003. http://dx.doi.org// 0.1093/eurheartj/eht296

3 Vasan RS. Biomarkers of cardiovascular disease: molecular basis and practical considerations. Circulation 2006; I I3:2335-62. http:// dx.doi.org/I0.1 I6I/CIRCULATIONAHA. 104.482570

4 Phelps ME. PET: the merging of biology and imaging into molecular imaging. J Nucl Med 2000; 41:66I-81.

5 Muntendam P, McCall C, Sanz J et al. The Biolmage Study: novel approaches to risk assessment in the primary prevention of atherosclerotic cardiovascular disease: study design and objectives. $\mathrm{Am}$ Heart J 2010; 160:49-57.el. http://dx.doi.org//0.1016/j.ahj.2010.02.02I

6 Joshi NV, Vesey AT, Williams MC et al. (I8)F-fluoride positron emission tomography for identification of ruptured and high-risk coronary atherosclerotic plaques: a prospective clinical trial. Lancet 2014; 383:705-12. http://dx.doi.org/I0.10I6/S0I406736(I3)6I754-7

7 Lin E, Alavi A. PET and PET/CT: a clinical guide. Stuttgart, New York: Georg Thieme Verlag; 2005.

8 Fox JJ, Strauss HW. One step closer to imaging vulnerable plaque in the coronary arteries. J Nucl Med 2009; 50:497-500. http:// dx.doi.org/I 0.2967/jnumed.108.056325

9 Knuuti J, Bengel FM. Positron emission tomography and molecular imaging. Heart $\mathrm{Br}$ Card Soc 2008; 94:360-7. http://dx.doi. org/l0.1136/hrt.2007.II8992

10 Tawakol A, Migrino RQ, Hoffmann $U$ et al. Noninvasive in vivo measurement of vascular inflammation with $\mathrm{F}$ - 18 fluorodeoxyglucose positron emission tomography. J Nucl Cardiol 2005; 12:294-301. http://dx.doi.org/I0.1016/j.nuclcard.2005.03.002

II Rudd JHF, Warburton EA, Fryer TD et al. Imaging atherosclerotic plaque inflammation with [18F]-fluorodeoxyglucose positron emission tomography. Circulation 2002; 105:2708-II. http://dx.doi. org/I0.II6I/0I.CIR.0000020548.60II0.76

12 Tawakol A, Migrino RQ, Bashian GG et al. In vivo I8F-fluorodeoxyglucose positron emission tomography imaging provides a noninvasive measure of carotid plaque inflammation in patients. J Am Coll Cardiol 2006; 48:I818-24. http://dx.doi. org/10.1016/j.jacc.2006.05.076

13 Pedersen SF, Graebe M, Fisker Hag AM et al. Gene expression and I8FDG uptake in atherosclerotic carotid plaques. Nucl Med Commun 2010; 31:423-9. http://dx.doi.org//0.1097/MNM.0b0 I3e32833767e0

14 Folco EJ, Sheikine Y, Rocha VZ, et al. Hypoxia but not inflammation augments glucose uptake in human macrophages: implications for imaging atherosclerosis with 18-fluorine-labeled 2-deoxy-Dglucose positron emission tomography. J Am Coll Cardiol 20II; 58:603-14. http://dx.doi.org/I0.1016/j.jacc.201 I.03.044 the specificity of imaging atherosclerotic plaques. This will advance our understanding of plaque biology and the effects of therapeutic interventions at the cellular level. With regard to delivering tailored patient care, the key advantage of imaging biomarkers is the additional anatomical data which helps localise and risk stratify individual atherosclerotic plaques. At present $18 \mathrm{~F}-\mathrm{NaF}$ imaging is the most promising prospect for being able to achieve the goal of prospectively identifying coronary plaques at high risk of rupture. This vision will hopefully be realised in the coming years with more widespread research in this area.

15 Yun M, Jang S, Cucchiara A et al. I8F FDG uptake in the large arteries: a correlation study with the atherogenic risk factors. Semin Nucl Med 2002; 32:70-6. http://dx.doi.org/I0.1053/snuc.2002.29279

16 Tahara N, Kai H, Yamagishi $\mathrm{S}$ et al.Vascular inflammation evaluated by [I8F]-fluorodeoxyglucose positron emission tomography is associated with the metabolic syndrome. J Am Coll Cardiol 2007; 49:1533-9. http://dx.doi.org/I0.10 I6/j.jacc.2006.II.046

17 Triant VA, Lee $\mathrm{H}$, Hadigan $\mathrm{C}$ et al. Increased acute myocardial infarction rates and cardiovascular risk factors among patients with human immunodeficiency virus disease. J Clin Endocrinol Metab 2007; 92:2506-12. http://dx.doi.org//0.1210/jc.2006-2190

18 Rasmussen LD, Engsig FN, Christensen $\mathrm{H}$ et al. Risk of cerebrovascular events in persons with and without HIV: a Danish nationwide population-based cohort study. AIDS 20II; 25:163746. http://dx.doi.org/I0.1097/QAD.0b013e3283493fb0

19 Subramanian S, Tawakol A, Burdo TH et al.Arterial inflammation in patients with HIV. JAMA 20I2; 308:379-86. http://dx.doi. org/l0.100I/jama.20I2.6698

20 Rominger A, Saam T, Wolpers S et al. I8F-FDG PET/CT identifies patients at risk for future vascular events in an otherwise asymptomatic cohort with neoplastic disease. J Nucl Med 2009; 50:16 I I-20. http://dx.doi.org//0.2967/jnumed.109.065I5I

21 Falk E, Sillesen $H$, Muntendam $P$ et al. The high-risk plaque initiative: primary prevention of atherothrombotic events in the asymptomatic population. Curr Atheroscler Rep 20I I; 13:359-66. http://dx.doi.org/I0.1007/s I I883-0I I-0193-0

22 Ben-Haim S, Kupzov E, Tamir A et al. Changing patterns of abnormal vascular wall F-I 8 fluorodeoxyglucose uptake on followup PET/CT studies. J Nucl Cardiol 2006; 13:79I-800. http://dx.doi. org/10.1016/j.nuclcard.2006.07.008

23 Tahara $\mathrm{N}$, Kai $\mathrm{H}$, Ishibashi $\mathrm{M}$ et al. Simvastatin attenuates plaque inflammation: evaluation by fluorodeoxyglucose positron emission tomography. J Am Coll Cardiol 2006; 48:1825-3I. http://dx.doi. org/10.1016/j.jacc.2006.03.069

24 Lee SJ, On YK, Lee EJ et al. Reversal of vascular I8F-FDG uptake with plasma high-density lipoprotein elevation by atherogenic risk reduction.J Nucl Med 2008; 49:1277-82. http://dx.doi.org// 0.2967/ jumed. 108.052233

25 Fayad ZA, ManiV,Woodward M et al. Safety and efficacy of dalcetrapib on atherosclerotic disease using novel non-invasive multimodality imaging (dal-PLAQUE): a randomised clinical trial. Lancet 20II; 378:I547-59. http://dx.doi.org/I0.1016/S0I40-6736(II)6I383-4

26 Rudd JHF, Myers KS, Bansilal S et al. Atherosclerosis inflammation imaging with 18F-FDG PET: carotid, iliac, and femoral uptake reproducibility, quantification methods, and recommendations. J Nucl Med 2008; 49:87I-8. http://dx.doi.org/I 0.2967/jnumed.107.050294

27 Rudd JHF, Myers KS, Bansilal S et al. (I8)Fluorodeoxyglucose positron emission tomography imaging of atherosclerotic plaque inflammation is highly reproducible: implications for atherosclerosis therapy trials. J Am Coll Cardiol 2007; 50:892-6. http://dx.doi. org/10.1016/j.jacc.2007.05.024 
28 Rogers IS, Nasir K, Figueroa AL et al. Feasibility of FDG imaging of the coronary arteries: comparison between acute coronary syndrome and stable angina. JACC Cardiovasc Imaging 2010; 3:38897. http://dx.doi.org/I0.1016/j.jcmg.2010.01.004

29 Cheng VY, Slomka PJ, Le Meunier L et al. Coronary arterial I8FFDG uptake by fusion of PET and coronary $C T$ angiography at sites of percutaneous stenting for acute myocardial infarction and stable coronary artery disease.J Nucl Med 20 I2; 53:575-83. http:// dx.doi.org/I0.2967/jnumed.I I I.097550

30 Wykrzykowska J, Lehman S, Williams G et al. Imaging of inflamed and vulnerable plaque in coronary arteries with I8F-FDG PET/CT in patients with suppression of myocardial uptake using a lowcarbohydrate, high-fat preparation. J Nucl Med 2009; 50:563-8. http://dx.doi.org//0.2967/jnumed.108.0556/6

3I Gaemperli O, Shalhoub J, Owen DRJ et al. Imaging intraplaque inflammation in carotid atherosclerosis with IIC-PKIII95 positron emission tomography/computed tomography. Eur Heart J 2012; 33: 1902-10. http://dx.doi.org/10.1093/eurheartj/ehr367

32 Tahara N, Mukherjee J, de Haas HJ et al. 2-deoxy-2-[(I8)F]fluoro-dmannose positron emission tomography imaging in atherosclerosis. Nat Med 2014; 20:215-9. http://dx.doi.org/10.1038/nm.3437

33 Otsuka F, Sakakura K, Yahagi $\mathrm{K}$ et al. Has our understanding of calcification in human coronary atherosclerosis progressed? Arterioscler ThrombVasc Biol 20 I4. http://dx.doi.org/ I0. I I6I/ATVBAHA. I I3.302642

34 Virmani R, Burke AP, Farb A et al. Pathology of the vulnerable plaque. J Am Coll Cardiol 2006; 47:CI3-18. http://dx.doi. org/10.1016/j.jacc.2005.10.065

35 Erbel R, Budoff M. Improvement of cardiovascular risk prediction using coronary imaging: subclinical atherosclerosis: the memory of lifetime risk factor exposure. Eur Heart J 2012; 33:120I-13. http:// dx.doi.org//0.1093/eurheartj/ehs076

36 Detrano RC,Wong ND, Doherty TM et al. Coronary calcium does not accurately predict near-term future coronary events in highrisk adults. Circulation 1999; 99:2633-8. http://dx.doi. org/I0.II6I/0I.CIR.99.20.2633

37 Bocksch WG, Schartl M, Beckmann SH et al. Intravascular ultrasound imaging in patients with acute myocardial infarction: comparison with chronic stable angina pectoris. Coron Artery Dis 1994; 5:727-35.

38 Beckman JA, Ganz J, Creager MA et al. Relationship of clinical presentation and calcification of culprit coronary artery stenoses Arterioscler Thromb Vasc Biol 2001; 21:1618-22. http://dx.doi. org/l0.1 I6I/hq090I.095554

39 Vengrenyuk Y, Carlier S, Xanthos S et al. A hypothesis for vulnerable plaque rupture due to stress-induced debonding around cellular microcalcifications in thin fibrous caps. Proc Natl Acad Sci U SA 2006; 103:14678-83. http://dx.doi.org//0.1073/pnas.06063/0I03

40 Nadra I, Boccaccini AR, Philippidis P et al. Effect of particle size on hydroxyapatite crystal-induced tumor necrosis factor alpha secretion by macrophages. Atherosclerosis 2008; 196:98-105. http:// dx.doi.org/I0.1016/j.atherosclerosis.2007.02.005

41 Czernin J, Satyamurthy N, Schiepers C. Molecular mechanisms of bone I8F-NaF deposition. J Nucl Med 2010; 5I:1826-9. http://dx. doi.org/I 0.2967/jnumed.II 0.077933

42 Rey C, Combes C, Drouet C et al. Bone mineral: update on chemical composition and structure. Osteoporos Int 2009; 20:101321. http://dx.doi.org//0.1007/s00198-009-0860-y

43 Beheshti M, Saboury B, Mehta NN et al. Detection and global quantification of cardiovascular molecular calcification by fluorol 8fluoride positron emission tomography/computed tomography - a novel concept. Hell J Nucl Med 20 I I; I4: I |4-20.

44 Derlin T, Richter U, Bannas P et al. Feasibility of I8F-sodium fluoride PET/CT for imaging of atherosclerotic plaque. J Nucl Med 2010; 5 I:862-5. http://dx.doi.org/ 10.2967/jnumed. I I0.07647I

45 Derlin T,Tóth Z, Papp L et al. Correlation of inflammation assessed by I8F-FDG PET, active mineral deposition assessed by I8F-fluoride $\mathrm{PET}$, and vascular calcification in atherosclerotic plaque: a dualtracer PET/CT study. J Nucl Med 20I I; 52:1020-7. http://dx.doi. org/I0.2967/jnumed.I I I.087452
46 Janssen T, Bannas P, Herrmann J et al. Association of linear I8F-sodium fluoride accumulation in femoral arteries as a measure of diffuse calcification with cardiovascular risk factors: a PET/CT study. J Nucl Cardiol 2013; 20:569-77. http://dx.doi. org/I0.1007/s I2350-0|3-9680-8

47 Dweck MR, Jones C, Joshi NV et al. Assessment of valvular calcification and inflammation by positron emission tomography in patients with aortic stenosis. Circulation 2012; 125:76-86. http:// dx.doi.org/I0. I I6I/CIRCULATIONAHA. I I I.05I052

48 Dweck MR, Jenkins WSA, Vesey AT et al. I8F-NaF uptake is a marker of active calcification and disease progression in patients with aortic stenosis. Circ Cardiovasc Imaging 20I4; 7:37I-8. http:// dx.doi.org/I0.1 I6I/CIRCIMAGING.II3.00I508

49 Dweck MR, Chow MWL, Joshi NV et al. Coronary arterial I8F-sodium fluoride uptake: a novel marker of plaque biology.J Am Coll Cardiol 20I2; 59:1539-48. http://dx.doi.org/I0.1016/j.jacc.201 I.12.037

50 Zhang Y, Cliff WJ, Schoefl Gl et al. Immunohistochemical study of intimal microvessels in coronary atherosclerosis. Am J Pathol 1993; 143:164-72.

5I Herrmann J, Lerman LO, Rodriguez-Porcel M et al. Coronary vasa vasorum neovascularization precedes epicardial endothelial dysfunction in experimental hypercholesterolemia. Cardiovasc Res 200I; 5I:762-6. http://dx.doi.org/I0.10I6/S0008-6363(0I)00347-9

52 Doyle B, Caplice N. Plaque neovascularization and antiangiogenic therapy for atherosclerosis. J Am Coll Cardiol 2007; 49:2073-80. http://dx.doi.org/I0.1016/j.jacc.2007.01.089

53 O'Brien ER, Garvin MR, Dev R et al. Angiogenesis in human coronary atherosclerotic plaques. Am J Pathol 1994; 145:883-94.

54 Moreno PR, Purushothaman KR, Fuster $V$ et al. Plaque neovascularization is increased in ruptured atherosclerotic lesions of human aorta: implications for plaque vulnerability. Circulation 2004; I I0:2032-8. http://dx.doi.org/I0.I I6I/0I.CIR.0000|43233.87854.23

55 Davies MJ, Thomas A. Thrombosis and acute coronary-artery lesions in sudden cardiac ischemic death. $N$ Engl J Med 1984; 310:1 137-40. http://dx.doi.org//0.1056/NEJMI98405033101801

56 Virmani R, Kolodgie FD, Burke AP et al. Atherosclerotic plaque progression and vulnerability to rupture: angiogenesis as a source of intraplaque hemorrhage. Arterioscler Thromb Vasc Biol 2005; 25:20546I. http://dx.doi.org/I0.II6I/0I.ATV.000017899I.7I605.18

57 Kolodgie FD, Gold HK, Burke AP et al. Intraplaque hemorrhage and progression of coronary atheroma. N Engl J Med 2003; 349:23 I6-25. http://dx.doi.org//0.1056/NEJMoa035655

58 Lancelot E, Amirbekian V, Brigger I et al. Evaluation of matrix metalloproteinases in atherosclerosis using a novel noninvasive imaging approach. Arterioscler Thromb Vasc Biol 2008; 28:425-32. http://dx.doi.org/I0.I I6I/ATVBAHA.I07.I49666

59 Kerwin W, Hooker A, Spilker M et al. Quantitative magnetic resonance imaging analysis of neovasculature volume in carotid atherosclerotic plaque. Circulation 2003; 107:85I-6. http://dx.doi. org/I0.II6I/0I.CIR.0000048I45.52309.3I

60 Brooks PC, Clark RA, Cheresh DA. Requirement of vascular integrin alpha $v$ beta 3 for angiogenesis. Science 1994; 264:569-7I.

6I Beer AJ, Haubner R, Sarbia M et al. Positron emission tomography using [18F]Galacto-RGD identifies the level of integrin alpha(v) beta3 expression in man. Clin Cancer Res 2006; 12:3942-9. http:// dx.doi.org/I0.I I58/1078-0432.CCR-06-0266

62 Beer AJ, Grosu A-L, Carlsen J et al. [18F]galacto-RGD positron emission tomography for imaging of alphavbeta3 expression on the neovasculature in patients with squamous cell carcinoma of the head and neck. Clin Cancer Res 2007; 13:6610-6. http://dx.doi. org/I0.I I58/I078-0432.CCR-07-0528

63 Beer AJ, Pelisek J, Heider P et al. PET/CT imaging of integrin $\alpha v \beta 3$ expression in human carotid atherosclerosis. J Am Cardiol Img 20I4 7:178-87. http://dx.doi.org/http://dx.doi.org/l0.1016/j. jcmg.2013.12.003

64 Antonov AS, Kolodgie FD, Munn DH et al. Regulation of macrophage foam cell formation by alphaVbeta3 integrin: potential role in human atherosclerosis. Am J Pathol 2004; 165:247-58. 